\title{
Diffuse Idiopathic Skeletal Hyperostosis of Cervical Column: a Clinical Anatomy and Functional Approach
}

\author{
Hiperostosis Esquelética Difusa Idiopática de la Columna Cervical: \\ una Aproximación Anatómica Clínica y Funcional
}

Néstor Alonso Perlaza

PERLAZA, N. A. Diffuse idiopathic skeletal hyperostosis of cervical column: a clinical anatomy and functional approach. Int. J. Morphol., 30(2):499-503, 2012.

SUMMARY: Diffuse Idiopathic Skeletal Hyperostosis is a condition of unknown cause, characterized by calcification and ossification of entheseal sites, which generally causes ankylosis of the spinal column and ossification of the extra-spinal ligaments or tendons. The case reported is from the cervical region of the spinal column of skeletal remains. Knowledge of the multiple clinical and functional implications analyzed is of great importance when approaching patients with said manifestations.

KEY WORDS: DISH; Cervical osteophyte; Ankylosis.

\section{INTRODUCTION}

Diffuse idiopathic skeletal hyperostosis (DISH) is a condition of unknown cause, characterized by calcification and ossification of entheseal sites, which generally cause spinal column ankylosis and ossification of the extra-spinal ligaments or tendons (Kim et al., 2011). This disease is predominant in males and typical in ages above 40 years (Mata et al., 1997; Wilczak \& Mulhern, 2010). It may be predisposed by sedentary lifestyles that lead to a body mass index with marked overweight (Verlaan et al., 2007) and type II diabetes mellitus (Espina et al., 2001).

The macroscopic characteristics to diagnose DISH on human osseous remains are: ossification of the anterior longitudinal ligament compromising at least three contiguous vertebrae, preservation of the spaces of the inter-vertebral discs and of the zygapophysial joints, and calcified extraspinal ligaments and muscular attachment (Kim et al.). These characteristics are same that should be considered for a radiological diagnosis (Resnick, 2002).

In some analyses performed on archaeological skeletal remains of members of the Medici family DISH was observed (Giufra et al., 2010), associating it to populations with high social status with protein-rich diets (Jankauskas, 2003). In the literature review by Mader et al. (2009), they suggest considering the extra-spinal manifestations of DISH to conduct a better characterization and diagnosis of the disease; these include Ischial tuberosity, iliac crests, pubic symphysis, trochanters, patella, femoral linea aspera, Achilles tendon attachment, and calcaneus (Aufderheide \& Rodriguez-Martin, 1998).

The clinical consequences in subjects with compromised cervical region of the spinal column frequently manifest progressively increasing cervicalgia; excessive ossification formation of the anterior longitudinal ligament (ALL) can generate dysphagia (Oppenlander et al., 2009), stridor (Papakostas et al., 1999), diminished range of motion (ROM) associated to ankylosis and cervical myelopathy (Mader, 2002).

The purpose of this report is to provide an analysis of the implications that can be endured by subjects with DISH, by using clinical and functional anatomy.

\section{CASE REPORT}

The human osseous remains correspond to vertebral segment of the cervical column of a contemporary adult individual, belonging to the skeletal collection in the Department of Morphology at Universidad del Valle. With only one osseous piece, the age estimated via the Albert \& Maples method (1995) was above 30 years of age (stage 4). 
Although they were fused, these cervical vertebrae (C5, C6, and C7) revealed a good state of preservation. Ossification of the anterior longitudinal ligament was observed with greater accentuation toward the right side of the spinal column (resembling candle wax) (Fig. 1). Likewise, it presented ossification of the posterior longitudinal ligament with slight narrowing of the vertebral canal at C5 level due to a marginal osteophyte.

Preservation of the articular space of the vertebral bodies joined by the inter-vertebral discs was not clearly

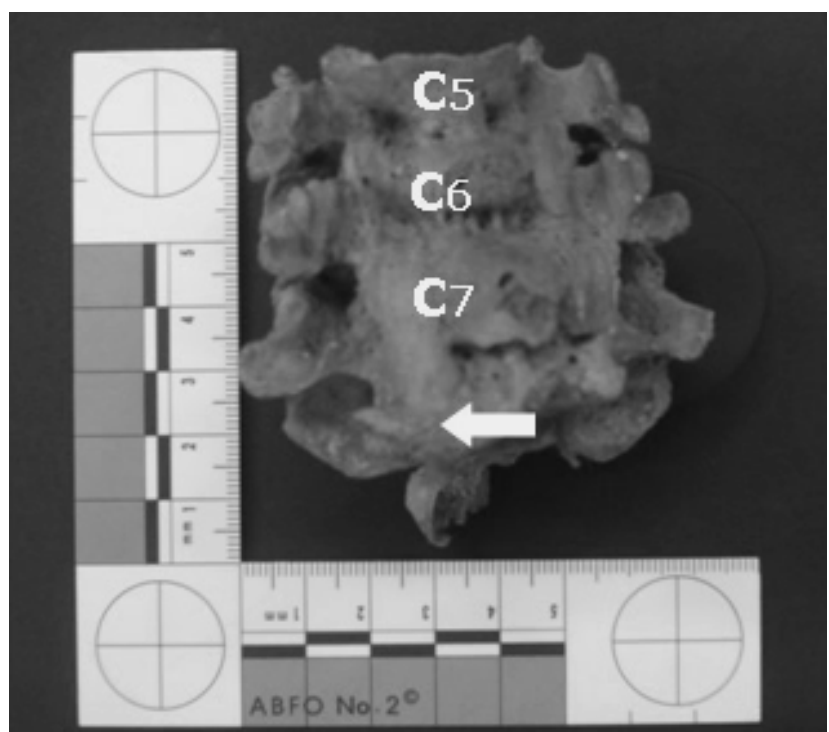

Fig. 1. Anterior view of the C5-C7 cervical vertebra segment. Observe ossification of the anterior longitudinal ligament and abundant new bone formation above $\mathrm{C} 7$ (arrow).

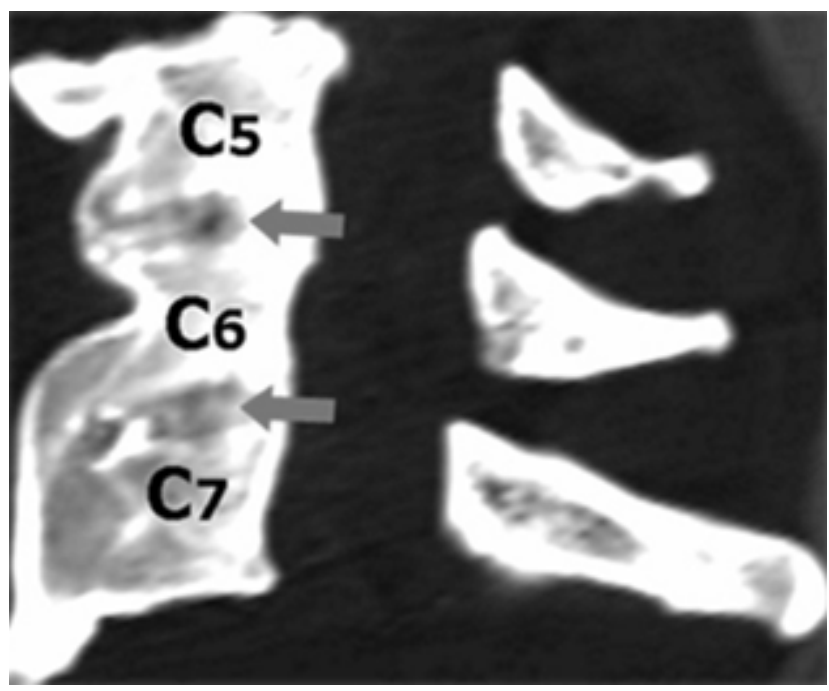

Fig. 2. Computerized tomography of the vertebral segment; arrows show the preservation of intervertebral disc spaces between $\mathrm{C} 5$ C6 and C6-C7. observable in situ, while the tomography image revealed this finding (Fig. 2). Preservation of the inter-vertebral spaces was found between the surfaces of the zygapophysial joints corresponding to C5-C6 and C6-C7. Upon closely observing the $\mathrm{C} 7$ vertebral body, a small depression was found on the left side of the anterior face, subjacent to the $\mathrm{C} 6$ transverse process and whose dimensions were 7 x $10 \mathrm{~mm}$ and $4 \mathrm{~mm}$ in depth (Fig. 3).

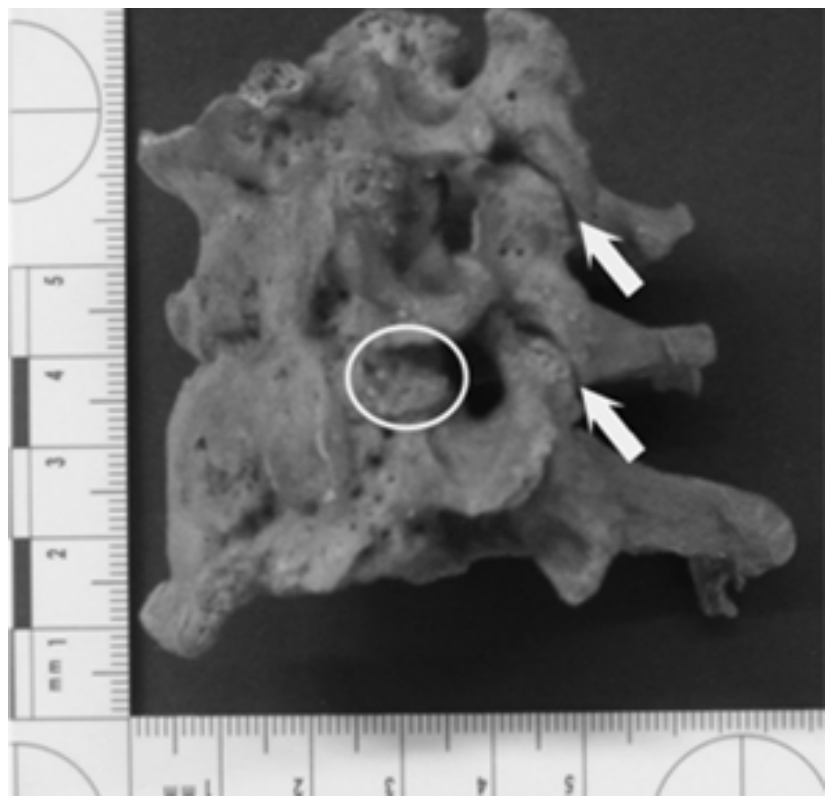

Fig. 3. Left lateral view. Preservation of C5-C6 and C6-C7 zygapophysial joints; note the depression on the lateral face of the C7 vertebral body (indicated by circle).

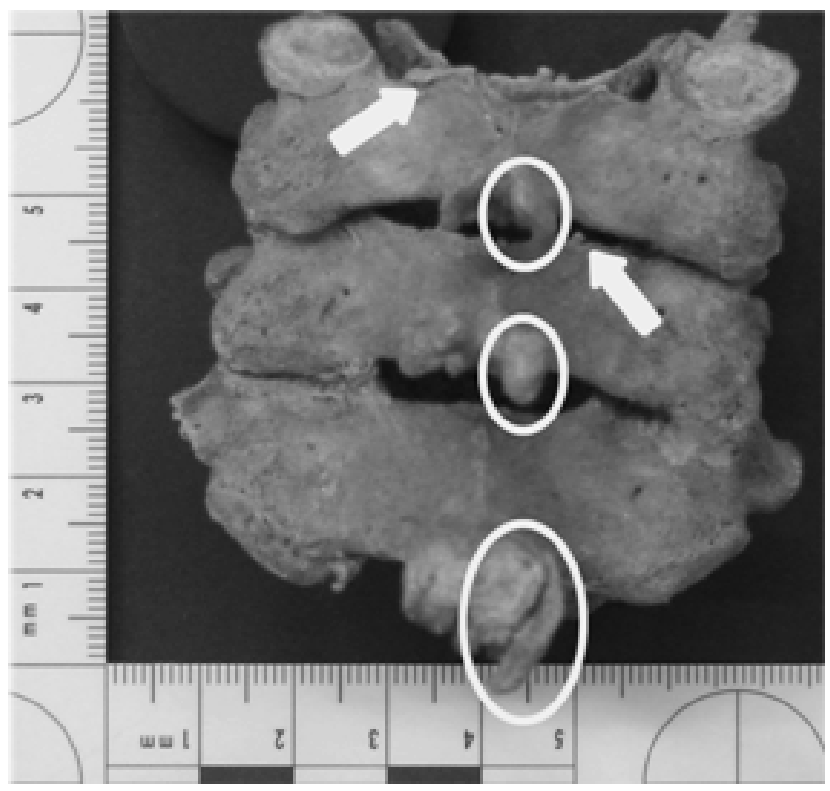

Fig. 4. Posterior view. Note ossification in extra-spinal ligaments (indicated by circles); arrows indicate the spurs above the lamina. 
Toward the upper border of the vertebral lamina, small spurs were observed - predominating in C5 and C6. Additionally, extra-spinal ossifications were observed on the anterior and posterior tubercles of the transverse processes, markedly so for C6; likewise, toward the bifurcation of the vertices of the spinous processes, mainly toward the tubercles of the right side and to a greater extent for C7 (Fig. 4).

\section{DISCUSSION}

Osteological identification. The spinal column is divided into five regions; the cervical vertebrae located on the skeletal neck form the cervical region. The vertebrae have general characteristics, common to all: body, vertebral foramen, arch, and apophysis. However, they have specific particularities in each region; in this case, the cervical region has the greatest mobility, given that it has small vertebral bodies, large and triangular vertebral foramen, transverse apophysis with transverse foramina, and anterior and posterior tubercles.

The vertebral arteries (VAs) and their accompanying veins pass through these foramina except for $\mathrm{C} 7$ where only accessory veins pass and, consequently, there the foramen is smaller or inexistent. Spinous apophyses are short and increase in size in descendant manner, with a bifurcated apex with two tubercles, rarely asymmetrical.

The uncinate process is typical of this group of vertebrae, found on the extremes of the upper face of the vertebral body (Latarjet \& Ruiz, 2004; White \& Folkens, 2005; Moore et al., 2010). With the previous anatomical references, we managed to identify that the fused osseous block corresponded to $\mathrm{C} 5, \mathrm{C} 6$, and $\mathrm{C} 7$ cervical vertebrae.

Clinical and functional considerations. The anterior longitudinal ligament (ALL) is a long fibrous lamina that joins the anterolateral surfaces of the inter-vertebral bodies and discs. In the cervical region, ALL occupies the space located behind the long neck muscles (Latarjet \& Ruiz; Moore $e t a l$. .). Ossification of the anterior longitudinal ligament, presented by the individual could have compromised several structures located in front of such. Studies by Oppenlander et al., reveal that the mechanical compression this alteration could exert on the esophagus is the predominant cause of dysphagia and, also, DISH was the main cause of said alterations for those patients. For this case report, the compression exerted by the $\mathrm{C} 5$-C6 vertebrae would affect the pharynx, given that anatomically the pharynx extends from the base of the cranium to the inferior border of the sixth cervical vertebra, the compression of C7 would occur on the proximal end of the esophagus.
Obstructions of the upper air way by extrinsic laryngeal constriction has been associated to ossification of the ALL in patients with DISH (Papakostas et al.; Caminos et al., 2008), where tracheotomy is continually required during emergency care of patients with respiratory distress due to laryngeal edema (Karkas et al., 2008).

Another independent condition, but which could be associated to DISH, is the ossification of the posterior longitudinal ligament (PLL). Although the degree of the narrowing of the spinal canal is not so marked because of the ossification of the PLL, some of the clinical and functional implications this subject could have endured due to neurological compression, inasmuch as the PLL is located inside the vertebral canal, behind the vertebral bodies to the sacrum, closely fixed to the inter-vertebral discs, go from: myelopathy and cervicalgia to diminished upper-limb muscle strength (Cheng et al., 1994; Mader).

The degree of functionality in activities of daily living (ADLs) in this subject was clearly affected because of the severely diminished range of motion (ROM) as a consequence of ankylosis of the cervical spine. Studies by Bible et al. (2010) report the Global ROM of the cervical spine as: flexion $63.4^{\circ}$, extension $38.7^{\circ}$, left lateral bending $38.9^{\circ}$, right lateral bending $37.4^{\circ}$, left axial rotation $55.8^{\circ}$, and right axial rotation $53.2^{\circ}$. Studies by McDonald et al. (2010) report the degrees of normal mobility in the lower cervical column: flexion- extension $28.9^{\circ} \pm 0.7^{\circ}$ at $\mathrm{C} 5$-C6, $17.4^{\circ} \pm 0.9^{\circ}$ at $\mathrm{C} 6-\mathrm{C} 7$. For rotation movements, these report $3.8^{\circ} \pm 0.6^{\circ}$ for $\mathrm{C} 5-\mathrm{C} 6$ and $4.0^{\circ} \pm 1.5^{\circ}$ for C6-C7.

Activities like descending stairs require greater percentage of ROM in flexion - extension and rotation than climbing up stairs; the transition from standing to sitting requires more lateral bending than going from sitting to standing. Personal hygiene activities (i.e., washing hands, washing hair) require greater percentage of ROM in all planes of movement than when performing activities like walking or descending stairs (Bible et al.); this individual had difficulty to independently participate within the context of daily life.

The lesion observed on the anterior face of the C7 vertebral body is consistent with a possible tortuosity of the vertebral artery (VA) on the left side, given that the changes of the arterial pressure can generate defects on the zone adjacent to the tortuosity. The VA originates from the first portion of the subclavian artery, penetrates the C6 transverse foramen, passing through the transverse foramina of the rest of the cervical vertebrae until passing through the foramen magnum, where it joins the opposite to form the basilar artery (Wladron \& Antoine, 2002; Latarjet \& Ruiz). The clinical 
implications to be considered with this alteration are mainly radiculopathy and vertebrobasilar insufficiency (Dahdaleh et al., 2010).

The analysis of the case reported suggests a severe degree of disability of the individual as a consequence of cervical DISH. Additionally, clinicians must consider the multiple clinical and functional implications of DISH when approaching patients with said manifestations.

ACKNOWLEDGEMENTS. The author expresses gratitude to the Department of Morphology at Universidad del Valle and to the TEBLAMI research group.

PERLAZA, N. A. Hiperostosis esquelética difusa idiopática de la columna cervical: una aproximación anatómica clínica y funcional. Int. J. Morphol., 30(2):499-503, 2012.

RESUMEN: La hiperostosis esquelética difusa idiopática es una afección de causa desconocida, caracterizada por calcificación y osificación de sitios de entesis, que generalmente ocasiona anquilosis de la columna vertebral y osificación de ligamentos o tendones. El caso reportado es a partir de la región cervical de la columna vertebral de un resto esquelético. El conocimiento de las múltiples implicaciones clínicas y funcionales analizadas es de gran importancia para el momento del abordaje de pacientes con dichas manifestaciones.

PALABRAS CLAVE: DISH; Osteofito cervical; Anquilosis.

\section{REFERENCES}

Albert, A. M. \& Maples, W. R. Stages of epiphyseal union for thoracic and lumbar vertebral centra as a method of age determination for teenage and young adult skeletons. $J$. Forensic Sci., 40(4):623-33, 1995.

Aufderheide, A. \& Rodriguez-Martin, C. The cambridge encyclopedia of human paleopathology. Cambridge, Cambridge University Press, 1998.

Bible, J. E.; Biswas, D.; Miller, C. P.; Whang, P. G. \& Grauer, J. Normal functional range of motion of the cervical spine during 15 activities of daily living. J. Spinal Disord. Tech., 23(1):15$21,2010$.

Caminos, C. B.; Cenoz, I. Z.; Louis, C. J.; Otano, T. B.; Esáin, B. F. \& Pérez de Ciriza, M. T. Forestier disease: an unusual cause of upper airway obstruction. Am. J. Emerg. Med., 26(9):1072.e1-3, 2008.

Cheng, W. C.; Chang, C. N.; Lui, T. N.; Lee, S. T.; Wong, C. W. \& Lin, T. K. Surgical treatment for ossification of the posterior longitudinal ligament of the cervical spine. Surg. Neurol., 41(2):90-7, 1994.

Dahdaleh, N. S.; Albert, G. W. \& Hasan, D. M. Multiple symptomatic vertebral artery loops treated with posterior cervical fusion. J. Clin. Neurosci., 17(6):788-90, 2010.

Espina, A.; Forcada, J. \& Joaniquet, X. Hiperostosis esquelética difusa idiopática, a propósito de un caso. Medifam, 11(8):481$585,2001$.

Giuffra, V.; Giusiani, S.; Fornaciari, A.; Villari, N.; Vitiello, A. \& Fornaciari, G. Diffuse idiopathic skeletal hyperostosis in the
Medici, Grand Dukes of Florence (XVI century). Eur. Spine J., 19(Suppl. 2):S103-7, 2010.

Jankauskas, R. The incidence of diffuse idiopathic skeletal hyperostosis and social status correlations in Lithuanian skeletal materials. Int. J. Osteoarchaeol., 13(5):289-93, 2003.

Karkas, A. A.; Schmerber, S. A.; Gay, E. P.; Chahine, K. N. \& Righini, C. A. Respiratory distress and vocal cord immobilization caused by Forestier's disease. Otolaryngol. Head Neck Surg., 139(2):327-8, 2008.

Kim, M.; Lee, I.; Kim, Y.; Oh, C.; Park, J.; Shin, M. \& Shin, D. H Diffuse idiopathic skeletal hyperostosis cases found in Joseon Dynasty Human Sample Collection of Korea. Int. J. Osteoarchaeol., 22(2):235-44, 2011.

Latarjet, M. \& Ruiz-Liard, A. Anatomía Humana. 4ª Ed. Buenos Aires, Panamericana, 2004. V.1.

Mader, R.; Sarzi-Puttini, P.; Atzeni, F.; Olivieri, I.; Pappone, N.; Verlaan, J. J. \& Buskila, D. Extraspinal manifestations of diffuse idiopathic skeletal hyperostosis. Rheumatology, 48(12):1478-81, 2009.

Mader, R. Clinical manifestations of diffuse idiopathic skeletal hyperostosis of the cervical spine. Semin. Arthritis Rheum., 32(2):130-5, 2002.

Mata, S.; Fortin, P. R.; Fitzcharles, M. A.; Starr, M. R.; Joseph, L.; Watts, C. S.; Gore, B.; Rosenberg, E.; Chhem, R. K. \& Esdaile, J. M. A controlled study of diffuse idiopathic skeletal hyperostosis. Clinical features and functional status. Medicine, 76(2):104-17, 1997. 
Moore, K.; Dalley, A. \& Agur, A. Clinically Oriented Anatomy. Philadelphia, WoltersKluwer/LippincottWilliams \& Wilkins, 2010

McDonald, C. P.; Bachison, C. C.; Chang, V.; Bartol, S. W. \& Bey, $\mathrm{M}$. Three-dimensional dynamic in vivo motion of the cervical spine: assessment of measurement accuracy and preliminary findings. Spine J., 10(6):497-504, 2010.

Oppenlander, M. E.; Orringer, D. A.; La Marca, F.; McGillicuddy, J. E.; Sullivan, S. E.; Chandler, W. F. \& Park, P. Dysphagia due to anterior cervical hyperosteophytosis. Surg. Neurol., 72(3):266-70, 2009

Papakostas, K.; Thakar, A.; Nandapalan, V. \& O'Sullivan, G. An unusual case of stridor due to osteophytes of the cervical spine: (Forestier's disease). J. Laryngol. Otol., 113(1):65-7, 1999.

Resnick, D. Diagnosis of bone and joint disorders. 4th ed. Philadelphia, Saunders, 2002.

Verlaan, J. J.; Oner, F. C. \& Maat, G. Diffuse idiopathic skeletal hyperostosis in ancient clergymen. Eur. Spine J., 16(8):1129$35,2007$.

Waldron, T. \& Antoine, D. Tortuosity or aneurysm? The palaeopathology of some abnormalities of the vertebral artery. Int. J. Osteoarchaeol., 12:79-88, 2002.

White, T. \& Folkens, P. The Human Bone Manual. San Diego, Elsevier Academic Press, 2005.

Wilczak, C. \& Mulhern, D. Co-occurrence of DISH and HFI in the Terry Collection. Int. J. Osteoarchaeol., DOI: 10.1002/oa.1218, 2012.
Correspondence to:

Dr. Néstor A. Perlaza

Department of Morphology

Universidad del Valle

Faculty of Health, Cali

COLOMBIA

Email: nestor_1007@hotmail.com

Received: 13-07-2011

Accepted: 31-01-2012 